\title{
Experiences from online and classroom education in hydroinformatics
}

\author{
I. Popescu, A. Jonoski, and B. Bhattacharya \\ UNESCO-IHE Institute for Water Education, Delft, The Netherlands
}

Correspondence to: I. Popescu (i.popescu@unesco-ihe.org)

Received: 24 December 2011 - Published in Hydrol. Earth Syst. Sci. Discuss.: 24 January 2012

Revised: 28 September 2012 - Accepted: 10 October 2012 - Published: 1 November 2012

\begin{abstract}
Universities and other higher education institutions involved in water-related engineering education are facing new challenges in offering lifelong learning services and online educational support. Both the curricula and the form of delivery are changing, as contemporary water problems require interdisciplinary approaches involving diverse and up to date expertise maintained via continuous professional development. Hydroinformatics education faces similar challenges in developing relevant curricula and finding appropriate combinations of course delivery to its target group. This article presents experiences from delivering two hydroinformatics courses in the fields of flood modelling for management (FMM) and decision support systems (DSS) in river basin management that in recent years have been delivered both online and in classroom settings. Comparisons between the two modes of delivery are provided, with the conclusion that online education in this field, although still faced with many challenges, has a promising potential for meeting future educational needs.
\end{abstract}

\section{Introduction}

Contemporary water-related engineering projects are characterised by high complexity and clear necessity of interdisciplinary approaches, which in turn requires a broader academic education as well as continuous professional development of modern-day engineers. Consequently, teaching demands are rapidly changing and they are currently significantly different compared to only five or ten years ago. This is a result of the diversification of disciplines, the shortage of skills in key areas and the needs for employability of the graduates.
In order to meet these new requirements and to make the European Higher Education Area attractive to students from all over the world, twenty-nine European countries signed the Bologna agreement in 1999. One of the most important changes introduced with this agreement is the European Credit Transfer System (ECTS), levelling education in Bachelor's and Master's, with 180 to 240 ECTS for Bachelor and 60 to 120 ECTS for Master level. Bachelor's and Master's Degrees are formulated with clearly defined learning outcomes and associated competencies, which can also serve for comparison of higher education among different universities and countries. The Bologna declaration also recognised that, in addition to the necessary changes in higher education, there is a clear need for lifelong learning and professional development, which is especially relevant for engineering education (Gonzalez and Wagenaar, 2003).

Water problems usually cut across boundaries, both geographical and professional, increasingly requiring alliances that link different professionals at many locations. Appropriate education for these new working modes becomes important for enhancing the capacity to manage water-related assets and the aquatic environment.

UNESCO-IHE (Delft, the Netherlands) is an academic, water education institute providing $\mathrm{MSc}$ and $\mathrm{PhD}$ education, as well as a large number of short courses and online courses (UNESCO-IHP, 1999). Since the institute primarily targets mid-career water professional, there is a clear recognition of the continuous tension between academic educational offering (embedded in larger degree programmes) and the requirements of professional competence development of those who work in a professional water sector environment (frequently for specialised, stand alone learning components). To better address the new demands students are increasingly 
being offered more flexibility in their future learning paths by providing some key components of water-related education through online courses. The advantages of online courses are that they are relatively cheaper (smaller tuition fees for the students), they provide flexible learning schedules, travel is not involved, families are not separated, etc. This approach in fact follows the general trend in education of gradually moving more towards asynchronous sharing of knowledge and reduction of direct contact with teachers (Price et al., 2007).

One of the fields where two online courses were developed at UNESCO-IHE is hydroinformatics. Two online courses in this field, which are the primary focus of this article, are flood modelling for management (FMM) and decision support systems (DSS) in river basin management (Jonoski and Popescu, 2012). These same courses are available as regular components of the Master studies in hydroinformatics delivered in a face to face setup. The transformation of these regular components into online courses requires significant efforts in both developing the learning material and supporting the online learning process of diverse groups of learners. Given that these are still relatively new developments in hydroinformatics education, this article presents the experiences from face to face (classroom) and online delivery of these two courses, which is useful for improving the effectiveness of future online learning. It needs to be noted that the face to face and online implementations of these courses run in parallel, however for different types of learners. They are consequently evaluated separately by the enrolled learners/students. So far, for these courses there is no structured pre-designed evaluation for direct comparison of the two modes of delivery. Nevertheless, the experiences presented herein provide some important lessons for future online learning in the field of hydroinformatics.

After this first introductory part the second section of the article introduces briefly the hydroinformatics field and its education implementation at UNESCO-IHE. The face to face and online implementations of the two courses are presented in Sects. 3 and 4, followed by discussions and conclusions in Sects. 5 and 6.

\section{Hydroinformatics education}

\subsection{The field of hydroinformatics and current educational approaches}

The concepts of Hydroinformatics as a new and distinct academic discipline were conceived and implemented by Professor Michael B. Abbott, about two decades ago (see, e.g. Abbott, 2001). Hydroinformatics has since been widely recognised internationally, attracted a successful series of biennial international conferences and has a peer reviewed journal.

Broadly, hydroinformatics can be defined as "the study of the flow of information and the generation of knowledge related to the dynamics of water in the real world, through the integration of information and communication technologies for data acquisition, modelling and decision support, and to the consequences for the aquatic environment and society and for the management of water based systems" (Abbott, 1991).

This definition includes merging of traditional fields of computational hydraulics with newer developments in numerical analysis, computer science, and communications technology. The fundamentals of hydroinformatics are in the water domain and they integrate knowledge and understanding of both water quantity and quality (Price et al., 2006). Furthermore, the field focuses on the integration of information about various water systems and the aquatic environment obtained from diverse sources, such as data from the field, remotely sensed data, and data from various hydraulic, hydrological and other kinds of numerical models. Aiming at the provision of decision support, typical hydroinformatics applications need to provide further integration with information and data coming from non-engineering fields like ecology, economy and social science. With these established goals, in recent years hydroinformatics has been transforming from a purely technical, into a sociotechnical discipline (Abbott and Jonoski, 1998; Jonoski, 2002).

The diversity of the involved technologies requires structured and goal-oriented development of hydroinformatics applications, which depends on appropriate educational approaches. Most adequate hydroinformatics expertise is commonly provided via educational programmes at MSc level (with duration of 1.5-2 yr) for BSc graduates from civil (hydraulic) or environmental engineering, computer science, or water-related earth sciences. Shorter hydroinformaticsrelated educational and training courses, often linked to the content of existing MSc programmes, are also provided. These are mostly targeting experts in need of continuous professional development (Kaspersma et al., 2012), dealing with rapidly evolving hydroinformatics technologies.

Hydroinformatics education at a Master level is provided by only few educational institutions in the world. The number of organisations that offer regular short courses or tailormade courses in this field is higher, but still rather limited. Consequently, attending hydroinformatics courses in the traditional classroom setting may be quite expensive for prospective participants. Especially professionals from developing countries may have significant difficulties in securing funds to follow such a course. New methods of transferring hydroinformatics education are therefore considered, such as group learning via web-based collaborative engineering (Molkenthin et al., 2001) or online courses, such as those presented in this article.

The example MSc specialisation in hydroinformatics from UNESCO-IHE can serve to introduce the common structuring of the content delivered in a typical hydroinformatics programme. The programme starts from the classical approach of developing mathematical models, based on first principles as a means for solving real engineering problems, 
and continues by introducing methods from new modelling paradigms such as data-driven or agent-based modelling. The introduction of information technology and software engineering topics is in parallel to these modelling topics. The different modelling approaches, together with their advantages and disadvantages are then demonstrated on different application areas. The structure of the programme together with the targeted application areas and associated tools and techniques are presented in Fig. 1.

This programme has a total duration of 18 months. The first 12 months cover the taught part of the programme structured in 14 educational components, so-called modules, each with duration of three weeks. During any particular module students are focusing on one group of thematically interrelated subjects. Many of these modules are also offered as stand-alone short courses for external participants who are not enrolled in the MSc programme. The last 6 months are reserved for individual research resulting in an MSc thesis. The time sequence of these educational components is presented in Fig. 2.

The presented content and structure, with minor modification from one academic year to another, is used in this programme for more than a decade. Other MSc programmes in hydroinformatics cover similar content, although with different structure. All these programmes, however, are faced with the continuous penetration of information and communication technologies in nearly all knowledge domains covered, and with their continuous and rapid changes. This situation requires rethinking and possibly adapting their contents and structure.

\subsection{Introducing more flexibility in hydroinformatics education}

A major challenge brought about by the evolution of hydroinformatics is that the volume of information that hydroinformaticians are called upon to know is increasing far more rapidly than the ability of engineering curricula to "cover it". The nature of this filed is such that graduates are required to master a broad spectrum of subjects, such as concepts from physics, mathematics, ecology, geography and computer and software engineering. This spectrum is well beyond the range of traditional hydraulic engineering curricula. Modelling and information and communication systems are at the core of hydroinformatics (which are quite specialised), but their adequate implementation for diverse application areas requires the coverage of a broad range of topics (Wagner et al., 2012).

For these reasons, structuring the curriculum that meets the needs of most hydroinformatics students appears to be an elusive goal. One solution is to institute multiple tracks for different areas of specialisation. In the example MSc programme presented in the previous section, this was realised by introducing a number of elective modules, covering a range of different topics. The courses that are subject of this article actually belong to these elective modules. For

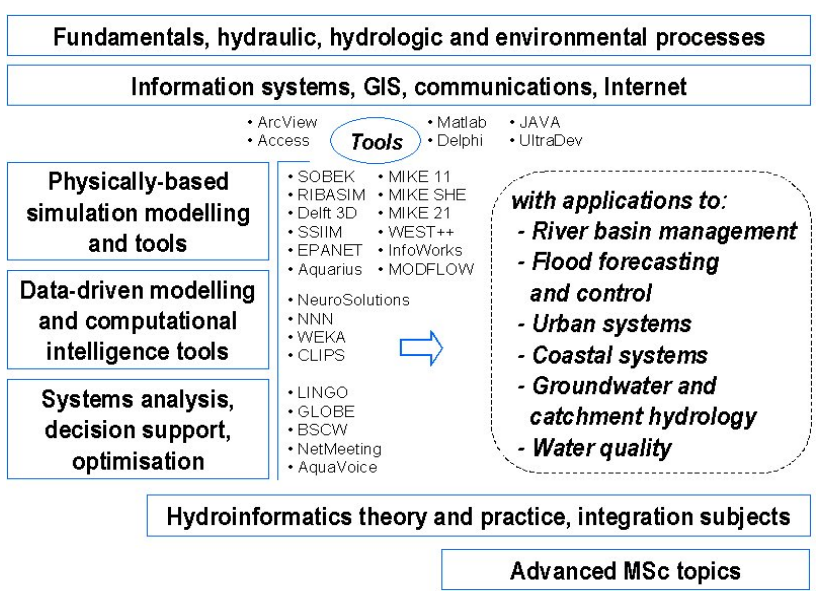

Fig. 1. General thematic structure of the Hydroinformatics MSc programme (taught part).

example, the "flood modelling for management" (FMM) is offered as an elective out of three other modules and the "decision support systems in river basin management" (DSS) is offered as an elective out of five other modules. These elective modules are offered as online courses as well. Once professionally engaged, hydroinformatics graduates can decide to enrol in such an online course (that they did not follow during their formal education) and improve their competences in a particular area. Equally, alumni of the institute or professionals who were not participants in an MSc programme, but they do want to acquire extra competencies can enrol in these online courses. With these arrangements the same content is delivered in a more flexible manner, meeting the needs of different learners interested in hydroinformatics topics.

A comparison of the pre-requisites, target group, learning outcomes and assessments between the two modes of course delivery is presented in Table 1. As can be seen from the table, the target audience in both online and face to face modes of delivery is the same, though in practice we observed that a large number of participants of the online courses were water professionals or $\mathrm{PhD}$ researchers who joined the course to improve their skills. In the face to face version of the courses all participants were MSc students, who might have had some professional experiences, but joined the course in the pursuit of obtaining an MSc degree.

\section{The FMM and DSS face to face modules}

The purpose of the FMM course is to provide professionals with the necessary background to appreciate the role and application of models in flood management, whereas the purpose of the DSS course is to present the general aspects of water resource management on the scale of the whole river basin (Jonoski and Popescu, 2012). These courses are modules in the regular Hydroinformatics MSc programme, but 


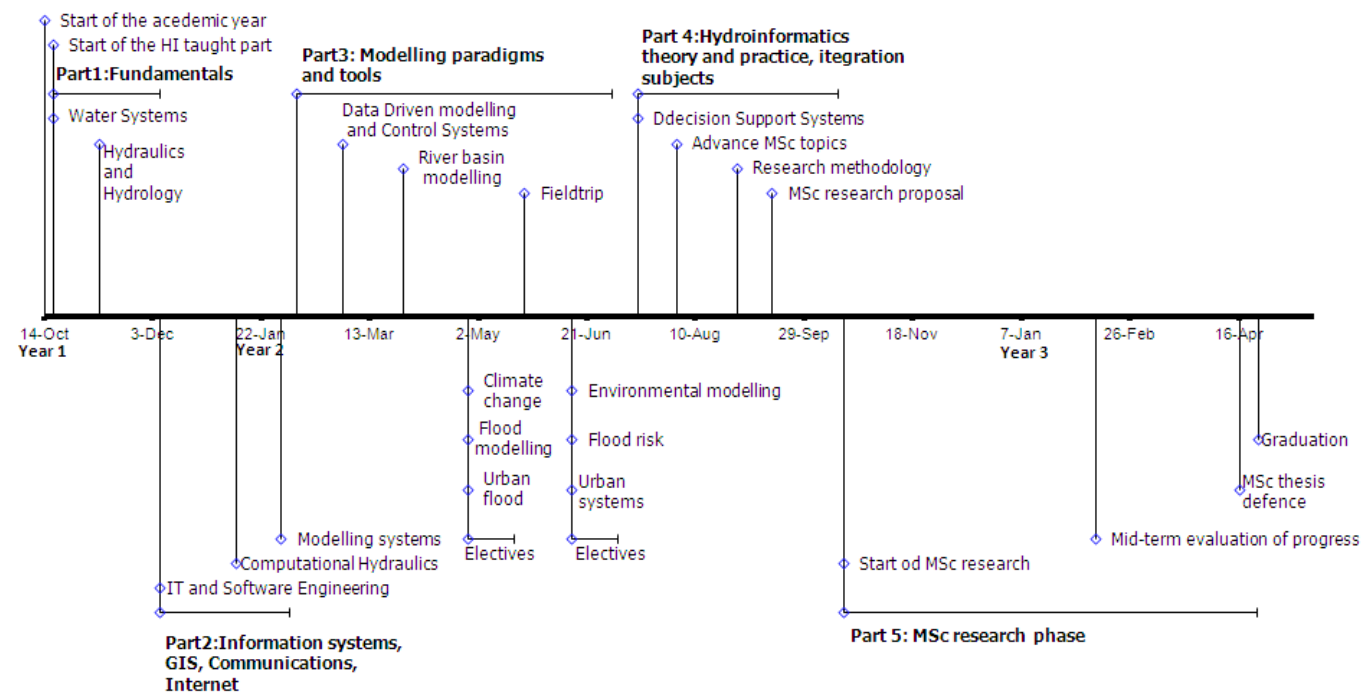

Fig. 2. Time sequence of the modules in the taught part and the research period of the MSc programme in Hydroinformatics.

Table 1. Comparison of key characteristics in the two modes of course delivery.

\begin{tabular}{|c|c|c|}
\hline Component & Face to face delivery of courses & Online delivery of courses \\
\hline Prerequisites & \multirow{2}{*}{\multicolumn{2}{|c|}{ Same for both modes of delivery }} \\
\hline Pre-requisites/target group & & \\
\hline \multicolumn{3}{|l|}{ Time and study load } \\
\hline Time of course delivery & 3 weeks (Study load 6-7 h day $^{-1}$ ) & 10 weeks $\left(2 \mathrm{~h} \mathrm{day}^{-1}\right)$ \\
\hline Estimated study load & $140 \mathrm{~h}$ & $140 \mathrm{~h}$ \\
\hline Learning objectives & \multicolumn{2}{|c|}{ Same for both courses } \\
\hline Assessment mode & Assignment and examination & Assignment \\
\hline European credit transfer load (ECTS) & 5 & 5 \\
\hline Certificate for the course & No & Yes \\
\hline \multicolumn{3}{|l|}{ Advantages/Disadvantages } \\
\hline Pace of learning & $\begin{array}{l}\text { Imposed by the timeframe of the } \\
\text { course (disadvantage) }\end{array}$ & $\begin{array}{l}\text { At students own choice } \\
\text { (advantage) }\end{array}$ \\
\hline Leave from work & $\begin{array}{l}\text { Student has to leave the work and } \\
\text { go to study (disadvantage) }\end{array}$ & $\begin{array}{l}\text { Student can study while working } \\
\text { (advantage) }\end{array}$ \\
\hline Direct interaction with instructor & Immediately (advantage) & Not in the same time (disadvantage) \\
\hline Direct interaction with instructor & $\begin{array}{l}\text { Answer given in an oral format } \\
\text { (disadvantage of not being } \\
\text { able to reconsult the answer) }\end{array}$ & $\begin{array}{l}\text { Instructor answers in a forum } \\
\text { (advantage of having the } \\
\text { answer for reviewing) }\end{array}$ \\
\hline
\end{tabular}

they are also offered to students from other relevant MSc specialisations. FMM and DSS modules are carried out for three weeks in module 8 and 11, respectively, and have curricula as defined in Tables 2 and 3. Due to its learning objectives, the DSS module is taught at a later stage, compared to the FMM module. In Tables 2 and 3, the "contact hours" represent the real contact hours between the lecturer and the students, while the "estimated study load" represents the estimated total number of study hours required for mastering a particular topic. The difference between study load hours and contact hours represents the number of hours that students need to allocate for studying without lecturers' supervision (self-study). The total number of ECTS is related to the number of study load hours of a module. Both DSS and FMM course have a load of five ECTS. 
Table 2. The content and assessment of the face to face FMM course.

\begin{tabular}{|c|c|c|c|c|c|}
\hline \multirow{2}{*}{ Subjects } & \multicolumn{3}{|c|}{ Contact hours [h] } & \multirow{2}{*}{$\begin{array}{l}\text { Estimated study } \\
\text { load }[\mathrm{h}]\end{array}$} & \multirow{2}{*}{ Assessment } \\
\hline & Lecture & Exercise & Workshop & & \\
\hline $\begin{array}{l}\text { Introduction to some application domains of } \\
\text { Hydroinformatics: floods, urban systems and } \\
\text { the environment }\end{array}$ & 4 & 0 & 2 & 14 & \\
\hline Climate change and its impact on hydrology & 4 & 0 & 2 & 14 & \\
\hline Environmental processes and water quality & 6 & 2 & 2 & 24 & \\
\hline Introduction to 1-D2-D, 2-D modelling & 2 & & 2 & 8 & \\
\hline $\begin{array}{l}\text { Flood analysis, river flood modelling and } \\
\text { 1-D flood routing }\end{array}$ & 10 & 22 & 0 & 74 & Exercise report (50\% weight) \\
\hline New data sources to support flood modelling & & 2 & 2 & 6 & \\
\hline Total study load hours & & & & 140 & Oral exam of all the subjects ( $50 \%$ weight) \\
\hline
\end{tabular}

Table 3. The content and assessment of the face to face DSS course.

\begin{tabular}{|c|c|c|c|c|c|}
\hline \multirow{2}{*}{ Subjects } & \multicolumn{3}{|c|}{ Contact hours $[\mathrm{h}]$} & \multirow{2}{*}{$\begin{array}{c}\text { Estimated study } \\
\text { load }[\mathrm{h}]\end{array}$} & \multirow{2}{*}{ Assessment } \\
\hline & Lecture & Exercise & Workshop & & \\
\hline System analysis in water resources & 8 & 6 & 6 & 42 & Exercise report ( $35 \%$ weight) \\
\hline Decision support systems & 6 & 4 & 4 & 30 & Exercise report ( $30 \%$ weight $)$ \\
\hline Software technologies for integration & 4 & 8 & 8 & 36 & Exercise report ( $20 \%$ weight $)$ \\
\hline Integration of weather prediction and water models & 8 & 2 & 4 & 32 & Exercise report ( $15 \%$ weight $)$ \\
\hline Total & & & & 140 & \\
\hline
\end{tabular}

The learning objectives of the FMM module are to

- understand and explain the main flood management problems;

- understand and explain the governing processes of flood generation and propagation;

- identify the proper modelling methodology for a given problem;

- utilise hands-on experience in the step-by-step modelling procedure (dealing with geometry, bathymetry, boundary conditions, forcing) for carrying out a practical study with river modelling software packages; and

- know how a river flood model may be used for structural and non-structural measures for flood mitigation.

With respect to its target group, the FMM course is designed for current and future water professionals (engineers and scientists), decision makers and others involved in flood modelling and flood management, particularly those who would like to be familiarised with the latest tools and techniques in flood modelling management.

The learning objectives of the DSS module are to

- understand the role of system analysis in water resources planning and management;

- formulate and solve water resources problems as optimisation problems;
- distinguish and properly use different types of decision support methods for water problems;

- build simple software applications that integrate data and models, both as stand-alone and Internet-based; and

- understand the potential of newly available data sources (e.g. remote sensing, web resources, data generated from climate and meteorological models) in advanced integrated modelling and decision support.

The target group of the DSS module are professionals who are developing modelling and information systems support for managing water resources in river basins or are involved in decision making processes in river basins at different levels.

The face to face FMM module is also offered as a short course. A participant to this short course joins the regular MSc programme, just for three weeks during the period of the module. The module is designed in such a way that water professionals, flood managers, or professionals who would like to know more about this topic, can join the MSc programme during this period, given that they meet certain prerequisites. In this case basic knowledge of hydrology and hydraulics is required. Some experience with flood modelling/management is desirable but not a must. 


\section{The FMM and DSS online courses}

\subsection{Main challenges in development of the courses}

The online modules on FMM and DSS are at postgraduate level, and they are with the same learning objectives and target groups as their face to face versions. The types of students are however different for the two modes of delivery. In the face to face modules, most participants are already enrolled MSc students and some short course participants, whereas in the online courses most students are water professionals from different countries of the world.

The first challenge in development and implementation of any online course is the development of suitable learning material. Traditional learning material, such as lecture notes, tutorials and exercises, already available for the face to face version of the courses, can be easily deployed for online learning. However, this is usually not sufficient for mastering the material by the distant learners. Enrichment by more effective learning material using suitable audio-visual material in electronic format is commonly needed. This requires a serious effort and the time required for developing such material should not be underestimated. For the courses presented here, for example, several man months of work were invested for this purpose.

Once suitable material is developed and deployed on a dedicated educational web-based platform, the advantages of the online courses can be realised. The course participants can download lectures, lecture notes, etc. at their own convenience and they can communicate with fellow participants and teachers using dedicated tools. For the FMM and DSS courses presented here the lectures are provided in the form of video, audio or slides with notes. A video lecture may contain slides with an audio of the teacher's commentary. Occasionally, it can contain a video window as well for displaying explanatory material (such as a movie). Theoretical lectures usually contain slides with notes. Soundtracks of lectures are incorporated in the presentation slides.

When it comes to the field of FMM and DSS, the development and implementation of online courses becomes further challenging, because these topics require not only the introduction of concepts, but also their exemplification by various software tools and systems, such as simulation models, encapsulated optimisation techniques, or MCA tools in case of the DSS course (Calizaya et al., 2010). Therefore, development and deployment of additional online learning material, specific for this purpose, may be required.

In the two implemented courses, modelling tools are introduced with instructional movies. Recent technologies allow such movies to be created easily and cheaply. The instructor presents the modelling tool by running it on his/her computer in a similar manner as in a face to face interaction. Current technologies can record the computer screen and add the instructor's voice to create the movie. Such movies can also be edited easily. Participants can download and follow these movies and become acquainted with the new tools. Because participants can run such a movie a number of times in order to master some specific features of a tool, experience shows that this is preferred to a classroom demonstration of a new tool. Nevertheless the inability to have live question and answer sessions (as in a classroom situation), which are frequently about concepts behind the introduced tools, leads to overall smaller appreciation of online learning when it comes to topics involving learning modelling tools.

This drawback can sometimes be overcome by using educational tools for synchronous discussions. Software tools such as Breeze or even Skype allow for arranging a realtime virtual classroom. During a virtual classroom, many-tomany communications in the form of video, voice and text enable everyone to see, talk and write (chat) to each other. Participants can share documents, computer screens or use a common electronic write board. In the implementation of the two courses presented here these virtual classrooms were not used, but they are being arranged at present times. It needs to be noted, however, that the number of participants when using such tools has to be limited.

Another important consideration related to online learning of modelling topics is the necessity of using public domain modelling tools. These are predominant in both the FMM and the DSS online courses presented here. Commercial modelling software is included for a few topics, but only using free, demo versions, without using any licence. Using full versions of such software can be easily arranged in a classroom setting, but the needed licences are commonly not available to distant learners. One alternative arrangement for overcoming this is the provision of web-based modelling simulations with the licensed software residing on the server side, which is also currently being considered.

Assessing students' performance is also an issue in online settings. In the face to face version of the presented course, the assessment consists of an oral examination, assignment reports on modelling exercises and classroom discussion. In an online version the oral examination cannot be conducted easily because it is difficult to organise a classroom for examination or to conduct an oral examination over the Internet. During initial runs of the courses an oral discussion was attempted using phone and Skype communication, but that turned out to be expensive and not easy to arrange. An alternative of involving other partner institutions in the country (or region) of the distant participant, where examinations can be organised is also currently considered. As a result, the current assessment in the FMM and DSS courses relies heavily on the evaluation of the assignment reports. This in fact necessitates re-adjusting of the learning objectives for the online courses, which are currently being contemplated.

\subsection{Implementation of the courses}

The FMM and DSS online courses were implemented as from 2006 and 2009, respectively. Since then they are run 
regularly once a year. The average time of running an online course is 10 weeks and the content of each course is the same as the corresponding face to face version. The online courses are carrying a load of 5 ECTS and they require the same amount of study hours as in a normal face to face course.

The admitted participants in both courses have always been with a minimum of a BSc degree in fields such as civil, environmental or agricultural engineering, earth sciences, computer science or systems engineering. Acceptance to the course is based on several criteria such as educational background, working experience and motivation expressed in the application. The participants are commonly capable of searching for the needed information, and motivated to develop the respective expertise relevant for their professional occupation. In other respects they are a very heterogeneous group: participants come from all over the world, the number of years of experience in the profession differs, as well as their experience with online learning.

Access to the online courses is via a dedicated educational web-based platform, set up using the open source Moodle software package (http://moodle.org/). The implemented platform is accessible through the UNESCO-IHE's e-learning campus at the following web address: http:// ecampus.unesco-ihe.org. Each admitted participant to an online course receives a user name and password for accessing the learning resources on the platform.

The learning resources of an online course are structured into units, where each unit addresses a certain topic. An example implementation of a unit dedicated to multi-criteria analyses in the DSS course is presented in Fig. 3. The advantage of such structuring using the Moodle platform is that the educational material is decomposed in its basic components and allows different people to use the same source material while each participant can have a different focus on individual units depending on their own expertise and insight.

As already mentioned, the lectures are provided in the form of videos, slideshows with audio, or slideshows with text explanations. Additional reading materials are also provided. Data and modelling software required are either provided from within the platform, or, in some cases the participants are directed to download the needed software from another web site.

The participants follow the lectures at their own pace. During the course they communicate with the lecturers and fellow participants using the functionalities of the platform. In the online environment the exchange between the instructors and the students is made via three ways of communication: a discussion forum where students pose questions, which are answered either by the lecturer, or by their fellow colleagues; a special forum called "Ask the teacher", where the lecturer answers the questions and the third option is an e-mail sent directly to the instructor.

All major units of the online courses include an assignment. Both FMM and DSS course have a set of 5-7

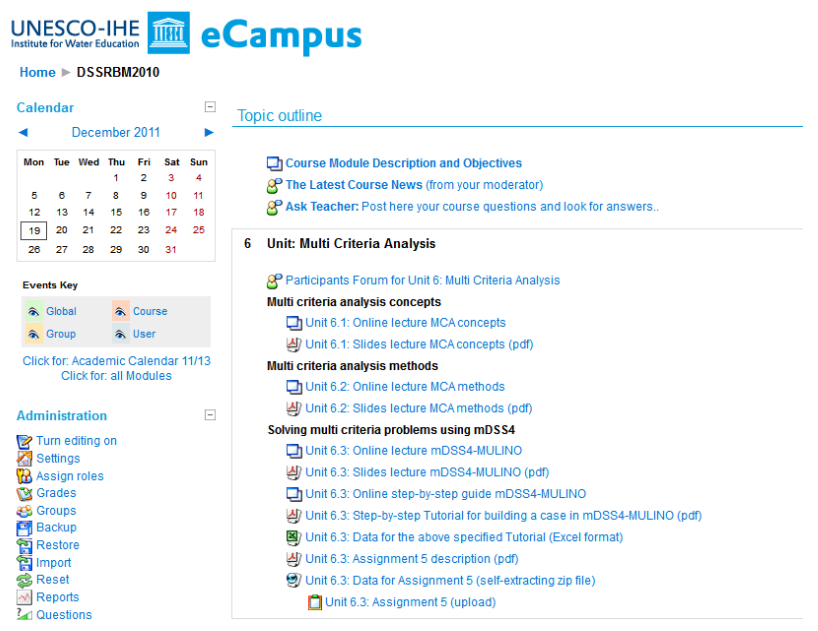

Fig. 3. Moodle implementation of the DSS course - Unit 6 (Multi Criteria Analyses).

assignments that participants have to carry out, and for which they have to submit (upload) reports according to a schedule presented in the course calendar available on the platform. After checking the assignment reports, the instructor provides grades to each participant individually, using the facilities of the platform. Passing grades for the assignment reports lead to successful completion of the course. At the end of an online course, every successful participant receives a certificate, which is a proof that they had followed the course actively and have been assessed through assignments. It needs to be mentioned that till now, the successful participants in FMM and DSS online courses do not automatically receive the ECTS credits when receiving a certificate. This is related to the issue of not having a formal examination in these online courses, as discussed earlier.

\section{Discussion on experiences of face to face versus online education}

The main educational challenge regarding the two courses described herein was how to structure the content of the course in such a way that the learning objectives are achieved, in both face to face and online mode of delivery. Main topics related to hydrological and hydraulic processes need to be presented to the students in a clear sequence. This is normal in face to face delivery, however, difficult to ensure in an online setting. In this case, once the learning material is deployed, students tend to jump in their learning activities from one topic to another, led by curiosity or confidence that some topics are already familiar to them. This can be controlled by introducing lectures and exercises gradually (hiding some topics for later introduction), but this is normally not appreciated by the students. In both modes of delivery exercises were introduced after each set of lectures 
Table 4. Appreciation of collaboration in online courses

\begin{tabular}{llc}
\hline What is your opinion on collaborative aspects during the course? & $\begin{array}{l}\text { FMM } \\
\text { (Completely) agree }\end{array}$ & $\begin{array}{l}\text { DSS } \\
\text { I had lively and stimulating discussions with other participants in the module. }\end{array}$ \\
\hline I learned a lot from other participants in the module. & $43.2 \%$ & $45.2 \%$ \\
Other participants in the module were able to answer my questions. & $48.6 \%$ & $61.9 \%$ \\
I provided useful help to other participants in the module. & $45.9 \%$ & $33.4 \%$ \\
I had feedback that this help to other participants in the module was useful. & $48.6 \%$ & $35.7 \%$ \\
\hline
\end{tabular}

to ensure that a particular topic is understood before a new topic was presented. Working with such exercises, to some extent, leads the students to follow a recommended sequence in mastering the topics.

In both the DSS and the FMM course, the approach to structuring of the content was based on the concept of competence-based learning, which ensures that final learning outcomes are achieved (Cheetam and Chivers, 2005). In this concept the whole learning process should be realised in such a way that the learning outcomes of the students lead to attainment of measurable competencies. Competencies are defined as final learning outcomes which demonstrate professional ability to perform given actions to a sufficient, recognised standard. This attainment can also be at different levels, but, in general, the attainment of a given competence is associated with a required minimum level of demonstrable evidence. It needs to be realised that even when using competence-based learning, prerequisites are important and certain learning sequence is preferred for the kinds of hydroinformatics topics, such as DSS and FMM. In this setting a recommended approach is to include extensive selfevaluation tests for each competence, which was not done so far for the two courses introduced here and remains to be introduced in the future. The design and development of content of the DSS course into competencies, so that understanding is achieved in a short period of time, is described in detail in Jonoski and Popescu (2012). A similar description for the FMM course is available in Popescu et al. (2009).

Structuring of the course content is especially important when it comes to modelling concepts, which represent major parts of both courses. These are first presented in a generic way so that the students can use them with any available software tool, no matter the graphical user interface implementation. In a face to face environment, because of the in-house licenses for commercial software for hydrological and hydrodynamic modelling (such as Mike SHE of DHI or Sobek of Deltares) students can have hands-on exercises and training on all types of tools. The difficulties with this approach for online courses, as already discussed, led to the usage of only open-source or freely available modelling tools. Experience shows that in both face to face and online courses the generic introduction of modelling concepts was adequate for their understanding and students can subsequently easily apply them when requested to solve problems in an exercise.

The key element that made a difference between the classroom education and the online education, in terms of guiding the students learning, is the online discussion forum, which due to its nature of exchanging information becomes, in a certain way, a study guide. Lecturers need to be very active and to follow closely what is posted on the forum because a non-reaction can be understood by the students as an approval. While other fellow students may provide the right guidance, for some questions the interventions from the lecturers are necessary. In a face to face environment this is not the case because students are following the key points emphasised by the lecturer and can ask immediate questions and clarifications.

Due to these differences, the time involvement of the academic staff in the face to face and online courses is also different. While in face to face settings most of the time is spent in a concentrated period of lecturing and exercise sessions, in online courses a prolonged commitment is required because they need to verify on a regular basis if there are questions and if they need to write elaborate answers. From a lecturer's point of view, it is not always clear to which extent certain notions are understood by the students, especially related to modelling concepts and their application.

The time investment of the student in an online course is designed to be the same as for a face to face course. The two courses, in both modes of delivery, presented herein, were designed in a classical teacher-centred approach where most of the learning is reached via information flow between the instructor and the learner. In both cases collaboration between students happens, either directly, or via the forum, and it is well appreciated by the students. The advantage of the online course is that the participants have a higher control on the time they spend for learning, while in a face to face course, due to the fact that the course is carried out for three consecutive weeks, the time for learning is clearly defined and stricter. A thorough evaluation of students' experiences with the two types of courses may provide further insights about the actual time that students spend on learning. Because the same students commonly would not take the same courses both online and face to face, a longer record with many more 
online participants is required for such analysis, which remains a task for the future.

As mentioned earlier, topics such as hydraulics, hydrology and decision support systems are better assimilated by the students if analysed and discussed in a group setting, through problem solving. This is done naturally in a face to face environment due to the fact that students share the same classroom, whereas the vehicle for such activities in an online environment is the earlier mentioned discussion forum, or similar tools. One of the major issues for an online course is therefore the level of attainment of the desired collaboration among participants.

In order to assess the collaboration level in the online courses, in the year 2009, participants to the online courses were asked to score six statements regarding collaboration on a five-point scale ( 1 - Do not agree, 2 - Partially agree, 3 - Neutral, 4 - Agree, 5 - Completely agree). The statements and the result of the scoring are presented in Table 4. When counting specifically the (completely) agreeing percentages, it can be seen that almost half of the participants tend to agree on having had good collaboration. For the DSS course we had 66 participants, of which 50 responded the questionnaire about collaboration, and in the case of the FMM course we had 94 participants and 80 responded the questionnaires. Looking at the overall numbers presented in Table 4 for the FMM course the statement of "I had lively and stimulating discussions with other participants in the pilot" has relatively the lowest score, but still one third agree (completely). In the DSS course $45.2 \%$ participants tend to agree (completely) with the same statement. The overall numbers for this course also give an indication of high collaboration, except that in this case smaller portion of participants agree that they have themselves provided help to others and received feedback (last two rows in Table 4).

In case of the face to face courses the evaluation of collaboration is done at the end of the MSc course, by direct discussion with students and by regular evaluations on the learning load and learning objectives.

\section{Conclusions}

When comparing face to face and online versions of the same courses the main challenge seems to be maintaining adequate structure of presentation of the course materials. While this is straight forward during face to face course delivery, for online courses this can be achieved by gradual introduction of the course material supported with adequate exercise assignments. This is especially important for modelling courses in which generic concepts need to be introduced before actual hands on exercises with modelling tools. In online courses the discussion forum plays a critical role for enhanced learning through peer collaboration as well as active participation of the involved lecturers. When adequately designed and implemented this approach can act as a substitute to the group problem solving sessions normally introduced in face to face courses. The evaluation of the courses presented in this article indicates a high level of students' appreciation of the collaboration realised in this manner.

There is still much to learn from the experiences with online education in hydroinformatics, such as how to produce interactive materials much more cheaply and effectively. UNESCO-IHE's experience is proving valuable in helping it to fulfil its international remit in education in hydroinformatics. The main challenging questions for the academic staff involved in conducting the online courses are how to measure students' learning and how to set up the online course in such a way that students' learning is facilitated.

The further development of the hydroinformatician depends upon adequate preparation, education and training. The latest technological developments that will determine the success or failure of major water-related projects are explicitly taken into consideration during the development of the hydroinformatics programme, and their achievements are directly used in the educational process and in implementation of numerous research projects. Dozens of the trained specialists have experienced that this programme is a very challenging, while at the same time rewarding undertaking that opens new horizons in their professional career.

Edited by: J. Seibert

\section{References}

Abbott, M. B.: Hydroinformatics: Information Technology and the Aquatic Environment, Aldershot, UK/Brookfield, USA: Ashgate, 1991.

Abbott, M. B.: Introducing hydroinformatics, J. Hydroinform., 1, 3-19, 2001.

Abbott, M. B. and Jonoski, A.: Promoting collaborative decisionmaking through electronic networking, Proc. 3rd Int. Conference on Hydroinformatics, Copenhagen, Denmark, 1998.

Calizaya, A., Meixner, O., Bengtsson, L., and Berndtsson, R.: Multi-criteria Decision Analysis (MCDA) for Integrated Water Resources Management (IWRM) in the Lake Poopo Basin, Bolivia, Water Resour. Manag., 24, 2267-2289, 2010.

Cheetam, G. and Cheevers, G.: Competence and informal learning, Edwar Elgar Press, 2005.

Gonzalez, J. and Wagenaar, R. (Eds.): Tuning Educational Structures in Europe, Final Report Phase One, Universidad de Deusto, Bilbao, 2003.

Jonoski, A.: Hydroinformatics as Sociotechnology: Promoting Individual Stakeholder participation by Using Network Distributed Decision Support Systems, Sweets \& Zeitlinger B.V., Lisse, The Netherlands, 2002.

Jonoski, A. and Popescu, I: Distance Learning in Support of Water Resources Management: an Online Course on Decision Support Systems in River Basin Management, Water Resour. Manag., 26, 1287-1305, 2012.

Kaspersma, J. M., Alaerts, G. J., and Slinger, J. H.: Competence formation and post-graduate education in the public water sector in Indonesia, Hydrol. Earth Syst. Sci., 16, 2379-2392, doi:10.5194/hess-16-2379-2012, 2012. 
Molkenthin, F., Holz, P. K., Belleudy, P., Jozsa, J., Price, R. K., and van der Veer, P.: HydroWeb: "WWW based collaborative engineering in hydroscience" - a European education experiment in the Internet, J. Hydroinform., 3 239-243, IWA Publishing, 2001.

Odgaard, A. J.: Trends and Current Developments in Hydraulic Engineering, Keynote lecture, National Chiao Tung University, Taiwan of China, 15-16 October 2001.

Popescu, I., Jonoski, A., Bhattacharya, B., and Keuls, C.: On-Line Competence Based Learning in Hydroinformatics at UNESCOIHE, Proceedings of the 8th International Conference on Hydroinformatics, Concepción, Chile, January 2009.

Price, R. K., Popescu, I., Jonoski, A., and Solomatine, D. P.: Fifteen years of experience in hydroinformatics at UNESCO-IHE Institute for Water Education, Proceedings of the 7th International Conference in Hydroinformatics, Nice, France, Research Publishing, 3101-3108, 2006.
Price, R. K., Bhattacharya, B., Popescu, I., and Jonoski, A.: Flood modelling for management: UNESCO-IHE's online course in hydrology, World Meteorological Organisation Bulletin WMO, 56, 102-106, 2007.

UNESCO-IHP: Water-Education-Training (W-E-T), A Sector Vision of Educators and Those to be Educated, Working Paper, UNESCO, Paris, 1999.

Wagener, T., Kelleher, C., Weiler, M., McGlynn, B., Gooseff, M., Marshall, L., Meixner, T., McGuire, K., Gregg, S., Sharma, P., and Zappe, S.: It takes a community to raise a hydrologist: the Modular Curriculum for Hydrologic Advancement (MOCHA), Hydrol. Earth Syst. Sci., 16, 3405-3418, doi:10.5194/hess-163405-2012, 2012. 